\title{
The artisanal and semi-mechanized mining sites of Burkina Faso (West Africa): a neglected window for collecting geoscientific information
}

\author{
RASHID ALI ISDINE DAO ${ }^{1}$ AND HERMANN ILBOUDO ${ }^{2}$ \\ ${ }^{1}$ Université Joseph KI-ZERBO \\ ${ }^{2}$ Université Ouaga I Professeur Joseph Ki-ZERBO \\ Presenting Author: dao_rashid@yahoo.fr
}

Artisanal gold mining, commonly referred to as "Gold Panning", has become, along with semi-mechanized mining, central activities in the economy of Burkina Faso. These activities are seen both as a source of poverty reduction for part of the community and as a cause of degradation of the social fabric and the environment. While the social consequences of these activities in West Africa have been relatively well studied for years, the documentation on their environmental consequences is more fragmented. As for research work on sustainable initiatives to supervise them, they are almost nonexistent in university studies. They appear to be a neglected window for collecting geoscientific information. However, they offer rich possibilities in information that can be exploited to improve geological and metallogenic knowledge, especially in environments without outcrops and highly disturbed by human action. So better exploration and exploitation of these mining sites will allow us to achieve these goals. The geoscientific information that can be collected at these sites goes through a well-established collection methodology. This methodology consists of geochemical and geophysical studies, SEM mineralogical analysis, remote sensing, isotopic tracing of elements in particular that of gold using an LA-ICP-MS analysis, geo -metallurgy and study of fluid inclusions at the origin of mineralization. All of this information collected at mining sites will help us establish and map metallogenic models for each site in order to establish exploration guides, as well as geoenvironmental models to prevent and limit environmental consequences. 